Paediatrica Indonesiana 15 : $207-210$. Jully - August 1975. 207

From the Department of Child Health, Sumber Waras Hospital.

University of 'Tarumanegara, Jakarta, Indonesia

\title{
Treatment of Cholera El Tor with Bactrim
}

by

S. KOMALARINI and J. ISWANDARI

\begin{abstract}
Between November 1971 and May 1974, there were 41 children, comprising 26 boys ard 15 girls, suffering from cholera $\mathrm{Bl}$ Tor gastroenteritis treated with parenteral Bactrim during the first 24 hours followed by Bactrim orally for 4 consecutive days. Rectal swabs on admission showed positive $V$. cholera biotype El Tor cultures in all cases; 9 children had adititional pathogentc $E$. coli in the stools. Besides Batrim, treatment consisted of intravenous administration of lactated Ringer's solution, dextrose $5 \%$ or saline. All the patients showed quick improvement of the clinical condition. Good result was founa in 34 children $(82.9 \%)$, fair in $6(14.6 \%)$, and failure in 1 case $(2.4 \%)$. All the children in this study survived. No drug intolerance or side effect was observed.
\end{abstract}

Received o 30 th. Nv. 1974 


\section{Introduction}

In Indonesia, diarrhoeal disease is one of the major health problems contributing highly to the morbidity and mortality rates. Bacterial infection is only a part of the aetiology of diarrhoeal diseases. Since 1970 the causative insolated organisms in our hospital were in the order of $\mathrm{V}$. cholera biotype $\mathrm{El}$ Tor (about $20 \%)$, enteropathogenic E. coli $(1.8 \%-7$. $0 \%)$, Shigella $(0.3 \%-0.9 \%)$ and Salmonella $(0.0 \%-0.3 \%)$ (Iswandari et al., 1973 \& 1974). In 1972 - 1973, V. parahaemolyticus were also isolated from the fecal specimens of the children admitted with gastroenteritis and dehydration (Komalarini and Joseph, 1975). These microorganims were found less frequent than $\mathrm{V}$. cholera or enteropathogenic E. coli, but more than Salmonella.

In a previous study in vitro, $V$. cholera of biotype El Tor was found to be highly sensitive to Bactrim (Njotosiswojo et al., 1972). At that time rectal swabs from 315 infants and children with gastroenteritis were examined, $60(19.0 \%)$ of which were caused by V. cholera, $22(7.0 \%)$ by enteropathogenic $\mathrm{E}$. coli, $10(3.2 \%)$ by Shigella and $1(0.3 \%)$ by Salmonella. V. cholera biotype El Tor was $100 \%$ sensitive to Bactrim, $96.7 \%$ were sensitive respectively to chloramphenicol and tetracycline, $80 \%$ to sulphadiazine and $73.3 \%$ to erythromycin. Similar results were obtained by Tanzil et al. (1970) and Bonang et al. (1970) in Jakarta. The present work is carried out to evaluate the efficacy of bactrim intravenously, followed by the oral route in order to compare with our previous experiences with tetracycline orally in the treatment of cholera El Tor in our Department.

\section{Material and Methods}

Forly-one cliildren with gastroenteritis and confirmed cholera El Tor in their stools admitted to the hospital between November 1971 and May 1974 were the subjects of this investigation. On each patient routine laboratory examinations were arranged on admission for: blood (haemoglobin, total and differential whiteblood cell counts, platelet count), urine and stools. Rectal swabs were done for cholera and other enteropathogens and repeated on the 3rd, 4th and 5th day of hospitalization. Blood examinations performed on admission were repeated on the 5 th day of hospitalization.

The fluid therapy used at the Sumber Waras Hospital consisted of initial I.V. rehydration (Ringer's lactate solution and dextros five percent in water or saline). Blood and plasma expanders were not routinely used. As soon as the patients' condition permitted, oral feeding with diluted milk formula or sieved food was started. During the first 24 hours of hospitalization, bactrim was given i.v. directly (infusion tube) in 25 cases or mixed with the appropriate intravenous solution in 16 cases twice a day at an interval of 12 hours. This was continued orally for 4 consecutive days. The dosage of intravenous bactrim was a quarter of an ampoule twice daily in infants less than 6 months old; half an ampoule for those between 6 months and six years, and one ampoule twice daily for children above 6 years. The dosage of oral bactrim was $6 \mathrm{mg} . /$ kg. body weight/day trimethoprim and $30 \mathrm{mg} . / \mathrm{kg}$. body weight $/$ day sulfamethoxazole divided into 2 equal doses and administered at an interval of 12 hours. All infants below 6 weeks of age were excluded from this study. Any local or general signs and symptoms of drug intolerance, if present; were recorded.

\section{Results}

Of the 41 cases, 26 were boys and 15 girls. Their ages ranged from $6 \frac{1}{2}$ months to 12 years. There were $9(22.0 \%)$ with moderate and 32 children $(78.0 \%)$ with severe dehydration. Associated disorders were present in 19 patients $(46 \%)$ and consisted of respiratory tract infections ( 6 cases), pulmonary tuberculosis ( 1 case), malnutrition (8 cases), anemia (2 cases), acute glomerulonephritis ( 1 case), and acute otitis media ( 1 case). Microscopic stool examination revealed the 
presence of Ascaris ova in 23 cases, Trichuris trichiura in 10 cases, and Hookworm in 1 case. Rectal swabs revealed 9 cases with addifional E. coli. Repeated stool cultures performed on the 3rd day still showed the presence of Vibrio cholera biotype El Tor in 9 children $(22.0 \%)$, but were negative on the 4 th and 5 th day of hospitalization. All the children showed quick improvement of the clinical condition; shock and dehydration disappeared on the 2nd day, The trial was defined as: good, when the children had no fever and normal frequency of the stool within 3 days of hospitalization, 34 cases $(82.9 \%)$; fair, when the stool became normal on the 4th or 5th day, 6 cases $(14.6 \%)$. One case $(2.4 \%)$ was considered a failure due to the presence of loose stool after 5 days of treatment, but the infant showed improvement of the general condition and shock. No vibrios were found in the rectal swab on the 2nd day.

All the children in this study survived.

No local irritation or drug intolerance or sideeffects were observed. The average hospital stay was 7.3 days.

\section{Discussion}

In a previous study of 49 children with gastroenteritis due to $\mathrm{V}$. cholera biotype $\mathrm{El}$ Tor treated with intravenous fluid and tetra- cycline orally, the mortality rate was $12.2 \%$. One child died in the first 24 hours of hospitalization (Iswandari et al., 1973).

Fluid and electrolytes replacement therapy is the most important aspect of treatment in diarrhoeal diseases. Antibiotics and chemotherapeutics are of value, only to shorten the duration and diminish the frequency of diarrhoea. It also reduces the duration of vibrios excreted in the stool and improves the management during the epidemics of cholera (Felsenfield, 1966; Gutman et al., 1969; Lindenbaum et al., 1967; Felisardo et al., 1969; Gharagozloo et al., 1970; Carpenter and Hirschhorn, 1972). Moreover in connection with the presence of secondary infections in our material, Bactrim seems to be useful not only in the treatment of the cholera infection, but also in the control of the associate diseases. The improved mortality rate could be explained by the additional use of intravenous Bactrim in combating. these infections.

\section{Acknowledgement}

The authors wish to thank Messrs F. Hoffman - La Roche Ltd., Basle, Switzerland and Roche Far East Research Foundation, Hong Kong, for the supply of Bactrim ampoules and tablets used in this study.

\section{REFERENCES}

1. BONANG, G., KANDOU, H., BARAMULI, C. and LINTONG, M.: Penentuan kepekaan vibrio El Tor, vibrio Cholera dan vibrio NAG terhadap trimethoprim - sulphamethoxazole dengan cara penipisan lempeng agar dst. oxoid Gan cara cakram. Maj. Kedok. Indones. 11 : 489 (1970).

2. CARPENTER, C.C.J. and HIRSCHHORN: Paediatric cholera: current concept of therapy. J. Pediatr. $80: 874$ (1972).
3. FELISARDO, F.O., ATIENZE, R., LOPEZ, W.L. and VILLEGAS, J.K. : Preliminary clinical experiences on the uso of antimicrobials in cholera El Tor. National symposium on the clinical efficacy of a new antimicrobial: Trimethoprim-sulphamethoxazole. Manila, Philippines, 1969.

4. FELSENEELD, O.: Review of recent trend in cholera research and control with annex on the isolation and identification of cholera vibrios. Bull. WHO 34 : 161 (1966). 
5. GHARAGOZLOO, R.A., NAFICY, K., MUIN, M., NASSIRZADAL, M.H. and YALDA, R.: Comparative trial of tetracycline, chloramphenicol and trimethoprim-sulphamethoxazole in eradication of vibrio cholerae El Tor. Br. med. J. 4 : 281 (1970).

6. GUTMAN, R.A., DRUTZ, D.J., WHALAE, G.E. and WATTEN, R.H. : Double-blind fluid therapy evaluation in paediatric cholera. Pediatr. 44 : 922 (1969).

7. ISWANDARI, J., ERAWAN, H., KOMALARINI, S. and NJOTOSISWOJO, S.: Cholera El Tor enteritis in Jakarta. Paediatr. Indones. 13 : 55 (1973).

8. ISWANDARI, J., KOMALARINI, S. and KHO, Is.K.: Parenteral Bactrim in the management of gastroenteritis in particular of cholera EI Tor in childhood. Asian J. Med, 10 : 125 (1974).
9. KOMALARINI, S. and JOSEPH, S.W.: Gastroenteritis due to Vibrio parahaemolyticus. Modern Med. 11 : 9 (1975).

10. LINDENBAUM, J., GREENOUGH, B.W. and ISLAM, M.R.: Antibiotic therapy of cholera. Bull. WHO $34: 871$ (1967).

11. NJOTOSISWOJO, S., KOMALARINI, S., ISWANDARI, J. and KHO, L,K: Sensitivity test of enterobacteriaceae in diarrhoeal diseases in Jakarta. South East Asian J. trop. med. (Publ. Hitls.) $3: 326$ (1972).

12. TANZIL, H.O.K., WARSA, R., ERFANI, ASSANI, S. and SURACHMAN: Muitidisks method for determining the sensitivity of microorganisms isolated from pathological specimens to Bactrim comipared with other antibiotics. Indones. J. (Publ. Hith.) $3: 54$ (1970). 